\title{
Parental Response to Only Children: Breaking the Stereotypes
}

\author{
Rona L. Levy ${ }^{1, *}$, Tasha B. Murphy ${ }^{1} \mathbb{D}$, Kendra Kamp ${ }^{2} \mathbb{D}$, Shelby L. Langer ${ }^{3}$ and Miranda A. L. van Tilburg ${ }^{1,4,5} \mathbb{D}$ \\ 1 School of Social Work, University of Washington, Seattle, WA 98105, USA; tbmurphy@uw.edu (T.B.M.); \\ vantilburg@campbell.edu (M.A.L.v.T.) \\ 2 School of Nursing, University of Washington, Seattle, WA 98195, USA; kamp@uw.edu \\ 3 Edson College of Nursing and Health Innovation, Arizona State University, Phoenix, AZ 85004, USA; \\ shelby.langer@asu.edu \\ 4 College of Pharmacy \& Health Sciences, Campbell University, Buies Creek, NC 27506, USA \\ 5 School of Medicine, University of North Carolina, Chapel Hill, NC 27599, USA \\ * Correspondence: rlevy@uw.edu; Tel.: +1-206-953-4269
}

Citation: Levy, R.L.; Murphy, T.B.; Kamp, K.; Langer, S.L.; van Tilburg, M.A.L. Parental Response to Only Children: Breaking the Stereotypes. Children 2021, 8, 605. https:// doi.org/10.3390/children8070605

Academic Editor: Dora Pereira

Received: 28 May 2021

Accepted: 15 July 2021

Published: 17 July 2021

Publisher's Note: MDPI stays neutral with regard to jurisdictional claims in published maps and institutional affiliations.

Copyright: (c) 2021 by the authors. Licensee MDPI, Basel, Switzerland. This article is an open access article distributed under the terms and conditions of the Creative Commons Attribution (CC BY) license (https:// creativecommons.org/licenses/by/ $4.0 /)$.

\begin{abstract}
While much has been written about the relationship between only child status and parents' behavior toward children, and consequent personality and intelligence, little is known about the relationship between only child status, parental response to illness, and subsequent child illness behavior. In this study, 227 mothers of 342 children completed measures designed to assess: (a) their children's school attendance, (b) their own psychological status, and (c) their own responses to their children's expressions of stomach pain. Parents of only children were more likely to minimize their children's gastrointestinal symptoms than were parents of children with at least one sibling. In addition, only children were less likely to miss school. Parental protectiveness did not differ as a function of only child status. These findings are somewhat discrepant with commonly held beliefs about parents' patterns of responding to only children.
\end{abstract}

Keywords: parenting; parental factors; birth order; school absences; social learning; illness behavior; protectiveness

\section{Introduction}

Much has been written about the effects of birth order, including only child status, on parents' behavior toward children and consequent personality, intelligence, and behavior development [1-4]. Certainly popular characterizations of parents' behaviors of only children have presented them as coddled or spoiled, receiving excessive amounts of attention, resulting in adverse traits. One very early 19th century researcher from Clark University in Massachusetts [5] reported that nearly all of his 200 survey respondents, when asked about only children they knew, described children without siblings as excessively spoiled. This perception continued, with the belief during the 20th century that an only "child would become overly sensitive and eventually a hypochondriac with weak nerves" [6].

Research in these areas has often found, in many cases contrary to popular beliefs, that the only child status has not been associated with poor outcomes in several areas [7-11]. For instance, a commonly held stereotype was that only children were more likely to be narcissistic; however, research indicates that only children have similar levels of narcissism as individuals with siblings $[9,10]$. Other research in both Western and non-Westernized countries has indicated that birth order has little impact on intelligence, personality, and risk aversion [12-14]. Studies which report significant associations between birth order and personality often have very small correlations $(r=0.02)$, leading authors to report the impact of birth order on personality is negligible [3].

With escalation in health care costs, among other factors, one important area which has received recent attention, but has been limited in the birth order literature, is the investigation of the phenomenon commonly called "illness behavior." Illness behavior is a term that refers to the way people perceive and react to somatic sensations (i.e., 
bodily sensations) which might signify disease [15]. Illness behavior falls on a continuum, ranging from failure to notice such sensations or refusal to let even serious illness interrupt one's normal routine, to misinterpretation of normal somatic sensations as symptoms of disease and seeking unnecessary medical treatment for minor complaints. Both ends of the continuum are of concern to health care providers: denial may lead individuals to postpone diagnostic investigations or to not adhere to medical regimens. Preoccupation with illness, on the other hand, creates a costly burden on the health care system [16,17].

Social scientists have been exploring whether illness behavior might be learned. For example, a child who grows up in a family with an ill parent may observe the parent's maladaptive illness behaviors (i.e., complaints, activity avoidance) and then emulate these behaviors themselves. Some support for this has come from findings that one form of illness behavior, health care utilization, tends to run in families. Lewis and colleagues [18] found that children's utilization of pediatric services was predicted by their mothers' healthcare utilization. Schor et al. [19] found, in 693 families enrolled in a prepaid health plan, significant correlations in uses of services among family members, especially at the extremes of usage. The influence of parental healthcare utilization on children's health care utilization for acute, chronic, and non-illness settings was 2.5 times higher for mothers compared to fathers. These familial utilization rates were correlated over six years of follow-up.

The concept of intergenerational transmission of illness behaviors was further explored by Levy and colleagues [20] and van Tilburg and colleagues [21] in studies of children of parents with Irritable Bowel Syndrome (IBS), a gastrointestinal complex of symptoms including chronic pain with no known etiology and high rates of disability [22-25]. They found children whose parents had a diagnosis of IBS had significantly higher healthcare utilization rates, not just for gastrointestinal symptoms but also for a wide range of somatic symptoms, as compared to a control group of children whose parents were not diagnosed with IBS. It is perhaps not surprising, then, that a recent systematic review of 27 studies of children with a chronically ill parent concluded that parental illness is related to increased somatic symptoms in children [26]. The relationship between increased somatic symptoms in children with chronically ill siblings was mixed, further highlighting the concept of intergenerational transmission [26].

Further research has explored the mechanisms by which this learning might occur. Using retrospective data, Whitehead et al. [27] found that subjects with IBS were more likely to report that when they had a cold as a child, their parents gave them toys, gifts, or treat foods such as ice cream, and those who received these rewards as children endorsed significantly higher levels of illness behavior. Using prospective data, Levy and colleagues [28] found that children whose mothers made protective responses to illness complaints independently reported more severe stomachaches and also had more school absences for stomachaches. In these studies and others [29-31], parental reinforcement of illness symptoms resulted in increased symptom complaints and doctor visits and reduced school attendance. Thus, child illness behaviors are associated with parental responses; however, what has rarely been studied is whether there are differences in child illness behaviors and parental response based on whether a child has siblings.

One early study found that mothers of pre-term and sick infants were more responsive to first-borns than later-borns such that first-born preterm and sick infants had more maternal simulation and responsiveness compared to later-born pre-term and sick infants [32]. Another study found that birth order was directly associated with the frequency of use of general practitioners [33]. Richards and Goodman [8] found that parents of only children in a psychiatric clinic differed from other parents in that they were more willing or able to seek medical advice. Similarly, Kushnir [34] concluded in a study of emergency room visits and birth order, that parental over-concern and protectiveness may predispose firstborns to perceive illness and painful situations as more stressful. In another study, Hawken [35] concluded that heightened parental concern was related to first-born children having a higher incidence of emergency room visits and hospitalizations following vaccinations. 
However, these studies were not designed to explore the specific ways these environmental mechanisms operate to shape these traits.

The current study sought to investigate whether parents respond differently to children's symptoms as a function of the children's only child status. Based on prior findings of greater parental concern for only children [1,11,36,37], we hypothesized that parents would show greater protectiveness to these children as compared to children with at least one sibling. Furthermore, based on our own research cited above into the effects of protectiveness, we also hypothesized that increased protectiveness would result in greater illness behavior, in the form of school absenteeism, on the part of these children.

\section{Materials and Methods}

\subsection{Participants}

The present report focuses on a subsample from a larger study that examined illness behavior and parental response of mothers both with a diagnosis of IBS ("Case" parents) and without a diagnosis of IBS ("Control" parents), a chronic gastrointestinal pain disorder [28]. In the parent study, IBS (case) families were randomly selected from an automated patient database at a large health maintenance organization (Group Health Cooperative in Seattle, WA, USA) to identify women diagnosed with IBS or abdominal pain during the preceding two years and who had 1 or more children between the ages of 8 and 15 . Trained telephone interviewers conducted further screening to ensure the mother met the Rome criteria for IBS (the Rome criteria are the current worldwide accepted symptom-based diagnostic criteria for IBS) [38]. Control families were selected from the database by identifying women who did not have a clinic visit during the preceding 2 years for IBS, abdominal pain, constipation, or diarrhea. Controls were further screened by telephone interview to ensure that neither the mother nor any adult family member met the Rome criteria for IBS. Cases were matched to controls with respect to age and number of children. Other inclusion criteria for both cases and controls included: the mother needed to be the child's legal guardian, and the child needed to have lived with the parent at least half of the time in the previous 2 years, presence of disability in the eligible child requiring full time special education, and no other family member had a diagnosis of ulcerative colitis or Crohn's disease. The subsample for the present study was derived by including only mothers who completed the questionnaires for all children in the family. This resulted in a subsample of 227 mothers of 342 children.

Study procedures were approved by the Institutional Review Board of Group Health Cooperative. All participants provided informed consent/assent.

\subsection{Measures}

Mothers completed pencil-and-paper questionnaires either in the clinic or in their home (their choice). Measures are described below.

School absences, doctor visits, and medication use. As a measure of illness behavior, mothers were asked to report the number of days during the past 3 months that their child missed school, the number of times the child visited a doctor, and the frequency of medication use as a result of abdominal pain. The response options for school absences and doctor visits were none, 1-3, 4-6, 7-9, or 10+. Response options for medication use were never, every month, every week, more than once a week, and every day. These variables were dichotomized as none (0) or 1 (one or more days). The decision to do so was based on the distribution of the responses.

Adult Responses to Children's Symptoms (ARCS) [39]. This scale, an extension of the Illness Behavior Encouragement Scale [40], assesses parental responses to child abdominal pain symptoms. Factor-analytically derived subscales include protectiveness (13 items) and minimization ( 7 items). Protectiveness measures parental encouragement of child illness behavior, putting the child in a sick role. Minimization measures parental criticism of child illness behavior, encouraging the maintenance of normal responsibilities. Exemplar items for protectiveness are: "When your child has a stomachache or abdominal pain, how often 
do you ... bring your child special treats or little gifts, ... let your child stay home from school, or ... tell others in the family not to bother your child or to be especially nice?" Exemplar items for minimization are: "When your child has a stomachache or abdominal pain, how often do you ... tell your child not to make such a fuss about it, ... try not to pay attention to your child, or ... insist that your child try to go to school?" Ratings are made on a $0-4$ (never to always) scale. Mean scores for each subscale are reported, with higher values indicative of greater protectiveness or minimization (theoretical range $=0-4$ ).

With respect to the psychometric properties of the scale, the developers report internal consistencies (Cronbach coefficient $\alpha$ ) of 0.87 for protectiveness and 0.67 for minimization [39]. Predictably, the two scales correlate inversely, $r=-0.22, p<0.01$ ). Validity of the protectiveness subscale is supported by its relationship to health care utilization for gastrointestinal symptoms [41].

The Symptom Checklist 90-R [42] measures global distress. We focused here on the depression (13 items), anxiety (10 items), and somatization (12 items) subscales. Respondents were asked to rate how much they were bothered by various symptoms during the prior seven days, including "headaches", "nervousness or shakiness inside", "the idea that something serious is wrong with your body", and "nausea or upset stomach". Items were rated with respect to their bothersomeness over the past 7 days, using a 0 (not at all) to 4 (extremely) scale. The developers report strong reliabilities. Internal consistencies (Cronbach coefficient alpha) range from 0.85 to 0.90 . Test-retest reliabilities range from 0.68 to 0.86 . Validity is also strong, as evidenced by appropriate relationships with other measures of the constructs, e.g., the Middlesex Hospital Questionnaire.

\subsection{Data Analysis}

Analyses were conducted using SPSS statistical software. Demographic and clinical characteristics for mothers and children were described using percentages and numbers for categorical data and mean and standard deviations for continuous variables. Unpaired t-tests were used to examine maternal protectiveness and minimization, and SCL-90 depression, anxiety, and somatization as a function of only child status (only child versus child with at least one sibling). Cross-tabulation and chi square analyses were used to examine school absences, doctor visits, and medication use as a function of only child status. A $p$-value of 0.05 was considered statistically significant.

\section{Results}

\subsection{Sample Demographics}

Tables 1 and 2 display the demographic and clinical characteristics of the sample. Children were, on average, 12 years old, $51 \%$ female, and $80 \%$ Caucasian. Forty percent were only children; $27 \%$, first born; $27 \%$, second born; $6 \%$, third born or higher. Fifty-four percent had experienced some degree of abdominal pain in the past two weeks. Mothers of only children were, on average, 44 years old, and mothers of multiple children were, on average, 43 years old. Similar to children, mothers of both only children and multiple children were predominantly (more than $80 \%$ ) Caucasian. Approximately half of the mothers (of both only children and multiple children) were college-educated, and more than $80 \%$ were employed either full time or part time. Additionally, $51 \%$ of mothers of only children had received a diagnosis of Irritable Bowel Syndrome compared to $46 \%$ of mothers of multiple children. Chi-square analysis found no significant differences between mothers of only children and mothers of multiple children for these demographic variables. Maternal living situation, however, differed between mothers of only children and mothers of multiple children; a greater percentage of mothers of only children were single mothers and had other adults living in the home compared to mothers of multiple children $\left(\chi^{2}=8.190(p<0.05)\right)$. 
Table 1. Demographic and clinical characteristics of the children $(n=342)$.

\begin{tabular}{lc}
\hline \multicolumn{1}{c}{ Age } & Mean = 12.03 (SD = 2.46) \\
\hline Gender(male) & $n=167(48.8 \%)$ \\
\hline Race/ethnicity, $n(\%)$ & $16(4.7 \%)$ \\
\hline Asian & $19(5.6 \%)$ \\
\hline African American & $16(4.7 \%)$ \\
\hline Hispanic & $3(0.9 \%)$ \\
\hline Native American & $274(80.1 \%)$ \\
\hline Caucasian & $11(3.2 \%)$ \\
\hline Other & $3(0.9 \%)$ \\
\hline Unknown & $137(40.1 \%)$ \\
\hline Birth order, $n$ (\%) & $205(59.9 \%)$ \\
\hline Only child &
\end{tabular}

Table 2. Demographic and clinical characteristics of the mothers $(n=227)$.

\begin{tabular}{|c|c|c|}
\hline & Mothers of Only Children & Mothers of Multiple Children \\
\hline & $(n=135)$ & $(n=92)$ \\
\hline Age & Mean $=44.35(\mathrm{SD}=7.43)$ & Mean $=42.55(\mathrm{SD}=5.14)$ \\
\hline \multicolumn{3}{|l|}{ Race/ethnicity, $n(\%)$} \\
\hline Asian & $6(4.4 \%)$ & $4(4.3 \%)$ \\
\hline African American & $9(6.7 \%)$ & $3(3.3 \%)$ \\
\hline Hispanic & $4(3.0 \%)$ & $5(5.4 \%)$ \\
\hline Native American & $1(0.7 \%)$ & $1(1.1 \%)$ \\
\hline Caucasian & $109(80.7 \%)$ & $75(81.5 \%)$ \\
\hline Other & $5(3.7 \%)$ & $3(3.3 \%)$ \\
\hline Unknown & $1(0.7 \%)$ & $1(1.1 \%)$ \\
\hline \multicolumn{3}{|l|}{ Educational status, $n(\%)$} \\
\hline$<$ High school & $4(2.9 \%)$ & $0(0.0 \%)$ \\
\hline High school degree & $6(4.4 \%)$ & $13(14.1 \%)$ \\
\hline \multicolumn{3}{|l|}{ Some college or } \\
\hline Technical school & $53(39.3 \%)$ & $34(37.0 \%)$ \\
\hline 4. -year college & $31(23.0 \%)$ & $18(19.6 \%)$ \\
\hline >College/Graduate & $40(29.6 \%)$ & $27(29.3 \%)$ \\
\hline \multicolumn{3}{|l|}{ School } \\
\hline Unknown & $1(0.7 \%)$ & $0(0.0 \%)$ \\
\hline \multicolumn{3}{|l|}{ Employment status, $n(\%)$} \\
\hline Unemployed & $19(14.1 \%)$ & $16(17.4 \%)$ \\
\hline Employed part-time & $22(16.3 \%)$ & $29(31.5 \%)$ \\
\hline Employed full-time & $92(68.1 \%)$ & $46(50.0 \%)$ \\
\hline Unknown & $2(1.5 \%)$ & $1(1.1 \%)$ \\
\hline
\end{tabular}


Table 2. Cont.

\begin{tabular}{lcc}
\hline & Mothers of Only Children & Mothers of Multiple Children \\
\cline { 2 - 3 } Age & $(\boldsymbol{n = 1 3 5 )}$ & $(\boldsymbol{n}=\mathbf{9 2})$ \\
\hline Living situation, $n(\%)$ & Mean $=\mathbf{4 4 . 3 5 ( S D = 7 . 4 3 )}$ & Mean $=\mathbf{4 2 . 5 5}(\mathrm{SD}=\mathbf{5 . 1 4})$ \\
\hline Single mom & $33(24.4 \%)$ & $11(12.0 \%)$ \\
\hline Other adult in home & $15(11.1 \%)$ & $7(7.7 \%)$ \\
\hline Married, spouse & $84(62.2 \%)$ & $73(79.3 \%)$ \\
\hline In home & & $1(1.1 \%)$ \\
\hline Separated & $2(1.5 \%)$ & $0(0.0 \%)$ \\
\hline Unknown & $1(0.7 \%)$ & \\
\hline Maternal IBS status, $n(\%)$ & $69(51.1 \%)$ & $50(45.7 \%)$ \\
\hline IBS case & $66(48.9 \%)$ & $54.3 \%)$ \\
\hline Control & & \\
\hline
\end{tabular}

\subsection{Maternal Responses to Illness Behavior}

Table 3 shows the results from the ARCS and SCL-90 questionnaires. While scores on the ARCS protectiveness subscale were slightly lower for mothers of only children (1.71 vs 1.79), these differences were not significant. Maternal minimization was higher for mothers of only children (1.13 vs. 0.98$)$; while these group differences approached significance, the effect size was not neligible.

Table 3. Maternal protectiveness, minimization, and distress as a function of only child status.

\begin{tabular}{cccccc}
\hline & $\begin{array}{c}\text { Only Child } \\
\text { Mean (SD) }\end{array}$ & $\begin{array}{c}\text { Child with Siblings } \\
\text { Mean (SD) }\end{array}$ & $\boldsymbol{t}$ & $\boldsymbol{p}$ & Effect Size * $^{*}$ \\
\hline ARCS protectiveness & $1.71(0.71)$ & $1.78(0.64)$ & -0.81 & 0.420 & 0.10 \\
ARCS minimization & $1.13(0.60)$ & $0.98(0.51)$ & 1.93 & 0.055 & 0.27 \\
SCL-90 anxiety & $0.61(0.67)$ & $0.40(0.47)$ & 2.72 & 0.007 & 0.36 \\
SCL-90 depression & $0.85(0.71)$ & $0.64(0.59)$ & 2.33 & 0.021 & 0.32 \\
SCL-90 somatization & $0.86(0.72)$ & $0.70(0.56)$ & 1.88 & 0.061 & 0.25 \\
\hline
\end{tabular}

* Cohen's d.

\subsection{Maternal Psychological State}

Table 3 also displays the results for SCL-90 depression, anxiety, and somatization. Mothers of only children reported significantly higher levels of depression (0.85 vs. 0.64, $p=0.02$ ) and anxiety (0.61 vs. $0.40, p=0.007)$ compared to mothers of multiple children, but there were no significant differences for somatization ( 0.86 vs. $0.70, p=0.061)$.

There were no differences in SCL-90 somatization scores by maternal race, marital status, number of children, child sex, or maternal age. There was a small, but significant correlation between SCL somatization scores and child age $(\mathrm{r}=0.16, p<0.05)$. Maternal education was associated with SCL-90 somatization. Mothers with a college education of less than 4 years reported higher somatization scores than mothers with a college degree (see Table 4). Maternal employment status (full-time vs. unemployed or part-time employment) was also associated with SCL-90 somatization. Full-time working mothers reported significantly higher somatization compared to unemployed/part-time working mothers (Table 4). Maternal IBS status was also associated with SCL-90 somatization: mothers with IBS reported significantly higher somatization than mothers without IBS (Table 4). 
Table 4. Significant $t$-test findings by demographics on SCL-90 subscales.

\begin{tabular}{|c|c|c|c|c|}
\hline & Mean (SD) & $t$ & $p$ & Effect Size * \\
\hline \multicolumn{5}{|l|}{ Somatization Subscale } \\
\hline Maternal education & & 2.11 & 0.04 & 0.27 \\
\hline$<4$ year college & $0.89(0.70)$ & & & \\
\hline College degree or higher & $0.71(0.61)$ & & & \\
\hline Maternal employment status & & -2.3 & 0.02 & 0.30 \\
\hline Full time & $0.87(0.72)$ & & & \\
\hline Unemployed or part-time & $0.68(0.55)$ & & & \\
\hline Maternal IBS status & & -8.66 & 0 & \\
\hline IBS diagnosis & $1.14(0.70)$ & & & \\
\hline No IBS diagnosis & $0.47(0.42)$ & & & \\
\hline \multicolumn{5}{|l|}{ Anxiety Subscale } \\
\hline Maternal IBS status & & -4.39 & 0 & 0.58 \\
\hline IBS diagnosis & $0.70(0.66)$ & & & \\
\hline No IBS diagnosis & $0.36(0.49)$ & & & \\
\hline Number of children & & 2.72 & 0.007 & 0.36 \\
\hline Only child & $0.61(0.67)$ & & & \\
\hline Multiple children & $0.40(0.47)$ & & & \\
\hline \multicolumn{5}{|l|}{ Depression Subscale } \\
\hline Maternal education & & 2.14 & 0.04 & 0.29 \\
\hline$<4$ year college & $0.86(0.73)$ & & & \\
\hline College degree or higher & $0.67(0.59)$ & & & \\
\hline Maternal IBS status & & -5.68 & 0 & 0.76 \\
\hline IBS diagnosis & $1.01(0.67)$ & & & \\
\hline No IBS diagnosis & $0.54(0.59)$ & & & \\
\hline Number of children & & 2.4 & 0.02 & 0.32 \\
\hline Only child & $0.85(0.71)$ & & & \\
\hline Multiple children & $0.64(0.59)$ & & & \\
\hline \multicolumn{5}{|c|}{$\begin{array}{l}\text { * Cohen's d multiple regression was used to determine the relative effect of the demographic variables. A } \\
\text { demographic variables (maternal race, education, marital status, employment status, IBS status, number o } \\
\text { children, child age, and child sex) were included in the regressions as predictor variables for each of the SCI } \\
90 \text { subscale scores. Maternal age, ethnicity, education, employment status, marital status, and child sex were use } \\
\text { in the regression model as dichotomous variables (maternal age } \leq 43 \text { or } 44+\text { based on median split; ethnicity } \\
\text { Caucasian or not Caucasian; education } \leq \text { college or } 4 \text {-year college degree or higher; marital status = married o } \\
\text { not married; employment = full time or part time/unemployed). }\end{array}$} \\
\hline
\end{tabular}

There were no differences in SCL-90 anxiety scores by maternal race, education, marital status, employment, age, or child sex. Child age was not significantly correlated with anxiety scores. Maternal IBS status, however, was associated with SCL-anxiety. Mothers with IBS reported significantly higher anxiety than non-IBS mothers (Table 4). Mothers of only children also reported significantly higher anxiety than mothers of multiple children (Table 4).

There were no differences in SCL-90 depression scores by maternal race, marital status, employment status, age, or child sex. Child age was not significantly correlated with depression scores. Maternal education was associated with SCL-90 depression scores: mothers with a college degree reported significantly less depression than mothers with a less than college education (Table 4). Maternal IBS status was also associated with SCL90 depression scores: mothers with IBS reported significantly higher depression scores than mothers without IBS (Table 4). Number of children was also associated with depression scores, with mothers of only children reporting significantly higher depression scores than mothers of multiple children (Table 4).

Standardized residuals were analyzed to identify any outliers, which showed that one participant needed to be removed for Somatization, four participants needed to be removed for Anxiety, and seven needed to be removed for Depression. Multicollinearity was not a concern with these data (Tolerance ranged from 0.85 to 0.97 for Somatization, from 0.81 to 0.96 for Anxiety, and from 0.91 to 0.96 for Depression, and VIF ranged from 1.02 to 1.17 for Somatization, from 1.04 to 1.232 for Anxiety, and from 1.04 to 1.23 for 
Depression). The data also met the assumption of independent errors (Durbin-Watson value $=1.84$ for Somatization, 1.98 for Anxiety, and 1.75 for Depression). Evaluation of the histogram and P-Plot of standardized residuals for all regressions indicated that the data were normally distributed. Finally, the scatterplot of standardized predicted values showed that the data met the assumptions of homogeneity of variance and linearity for all regressions (Appendix A).

Using the enter method, we found that the demographic variables in the model explained a significant amount of the variance in SCL-90 Somatization $(F(9208)=10.44$, $p<0.001, \mathrm{R}^{2}=0.31, \mathrm{R}^{2}$ Adjusted $\left.=0.28\right)$, Anxiety $\left(\mathrm{F}(9205)=4.32, p<0.001, \mathrm{R}^{2}=0.16\right.$, $\mathrm{R}^{2}$ Adjusted $\left.=0.12\right)$, and Depression $\left(\mathrm{F}(9203)=7.52, p<0.001, \mathrm{R}^{2}=0.25, \mathrm{R}^{2}\right.$ Adjusted $\left.=0.22\right)$. The analysis showed that maternal IBS status and number of children significantly predicted somatization, anxiety, and depression (see Table 5). Child age also predicted somatization.

Table 5. Multiple regression predicting SCL-90 scores.

\begin{tabular}{|c|c|c|c|c|}
\hline SCL-90 Subscale & Predictor & $\beta$ & $\mathbf{T}$ & $p$ \\
\hline \multirow{9}{*}{ Somatization } & Maternal IBS Status & 0.48 & 8.04 & $<0.001$ \\
\hline & Child Age & 0.18 & 2.94 & $<0.01$ \\
\hline & Child sex & 0 & -0.01 & ns \\
\hline & Maternal Age & 0.01 & 0.2 & ns \\
\hline & Maternal Ethnicity & -0.08 & -1.41 & ns \\
\hline & Maternal Education & -0.01 & -0.09 & ns \\
\hline & Marital status & 0.01 & 0.04 & ns \\
\hline & Employment status & 0.05 & 0.83 & ns \\
\hline & Number of children & -0.13 & -2.19 & $<0.05$ \\
\hline \multirow{9}{*}{ Anxiety } & Maternal IBS Status & 0.33 & 4.96 & $<0.001$ \\
\hline & Child Age & 0.09 & 1.25 & ns \\
\hline & Child sex & 0.03 & 0.44 & ns \\
\hline & Maternal Age & -0.01 & -0.08 & ns \\
\hline & Maternal Ethnicity & -0.05 & -0.7 & ns \\
\hline & Maternal Education & 0.01 & 0.16 & ns \\
\hline & Marital status & 0.06 & 0.84 & ns \\
\hline & Employment status & -0.02 & -0.35 & ns \\
\hline & Number of children & -0.18 & -2.64 & $<0.01$ \\
\hline \multirow{9}{*}{ Depression } & Maternal IBS Status & 0.4 & 6.24 & $<0.001$ \\
\hline & Child Age & -0.05 & -0.74 & ns \\
\hline & Child sex & 0.07 & 1.14 & ns \\
\hline & Maternal Age & 0.01 & 0.06 & ns \\
\hline & Maternal Ethnicity & -0.11 & -1.71 & ns \\
\hline & Maternal Education & -0.07 & -1.07 & ns \\
\hline & Marital status & 0.1 & 1.49 & ns \\
\hline & Employment status & 0.01 & 0.15 & ns \\
\hline & Number of children & -0.16 & -2.55 & $<0.05$ \\
\hline
\end{tabular}

\subsection{School Absences, Health Care Visits, and Medication Use}

School absences, healthcare visits, and medication use were analyzed for the full sample of 342 children, as these variables are child-specific. Overall, $72.5 \%$ percent of children represented in the sample missed no days of school, 24.3\% missed 1-3 days, and $4 \%$ missed 4 or more days. Similarly, $90.1 \%$ of children did not visit a doctor $(8.5 \%$ had one visit, $1.5 \%$ had two or more visits), and $72.7 \%$ did not use medication during the prior 3 months ( $23.3 \%$ used medication every month, and $3.9 \%$ used medication at least once per week).

A cross-tabulation was used to examine the number of school days missed in the past three months due to stomachaches or abdominal pain (coded 0 for none and 1 for one or more) as a function of only child status. Children with siblings were more likely to miss school as compared to only children (33.2\% versus $19.0 \%$; see Table 6 below). 
Table 6. Crosstabs for school days missed, doctor visits, and medication use.

\begin{tabular}{ccccc}
\hline & Only Child & Multiple Children & $\chi^{2}$ & $p$ \\
\hline $\begin{array}{c}\text { Missed School Days } \\
n\end{array}$ of sample & 26 & 68 & & \\
$\%$ of & $19.00 \%$ & $33.20 \%$ & & $<0.01$ \\
$n$ & & & & \\
$\%$ of sample & 14 & 20 & 0.02 & $\mathrm{~ns}$ \\
\hline $\begin{array}{c}\text { Medication Use } \\
n\end{array} \%$ of sample & $10.20 \%$ & $9.80 \%$ & & \\
\hline & 38 & 51 & 0.25 & $\mathrm{~ns}$ \\
\hline
\end{tabular}

In addition to school days missed, mothers reported on the number of days their child visited the doctor for stomachaches/abdominal pain (coded 0 for no visits and 1 for one or more visits) and the frequency of medication use for stomachaches or abdominal pain (coded 1 for took no medications and 1 for took medications at least once/month) during the past 3 months. Regarding doctor visits, $10.2 \%$ of only children and $9.8 \%$ of children with siblings visited the doctor within the prior 3 months. Regarding medication use, $28.8 \%$ of only children and $26.3 \%$ of children with siblings took medicine for stomachache or abdominal pain within the prior 3 months. A cross-tabulation comparing only children and children with siblings was not significant for either doctor visits or medication use (Table 6).

\section{Discussion}

Prior studies in the literature have shown that parental protectiveness in response to illness behavior is related to increased symptoms and disability. We hypothesized that parents of only children would exhibit greater protectiveness than parents of multiple children. The present study, however, did not find parents more protective in response to only children's symptom complaints. We also found no differences in doctor visits or medication use (which might be seen as protective behaviors) between only children and children with siblings. These findings are somewhat discrepant with commonly held beliefs that parents tend to be over-protective toward only children. They are also inconsistent with Richards and Goodman's [8] finding of parents of only children being more willing or able to seek medical advice. However, their study only found increased health care seeking by parents of only children, not the specific form of responses we were investigating. Arguably, these day-to-day interaction behaviors may have a more significant impact on personality than doctor visits. In addition, in the Richards and Goodman study, health care seeking referred to psychiatric care and thus may not generalize to other medical situations.

Overprotective parenting includes doing tasks for children that they developmentally should be able to do themselves, as well as removing barriers and potential harms that children developmentally can manage themselves. Overprotective parenting has been associated with a host of negative outcomes for parents and children. For example, parental overprotectiveness has been associated with child anxiety, behavior disorders, suicidality, adolescent alcohol use, and increased child pain behaviors [43-47]. Yet, it has universal appeal in society today: overprotective parenting is often agreed upon as 'good parenting' by people across socioeconomic classes [48]. This may explain why protectiveness would not differ between parents with an only child and parents with multiple children. Overprotective parenting is culturally expected and therefore applied equally to all children. 
We did not find differences in protectiveness between parents of only children and parents of multiple children. While we also did not find differences in parental minimization of child symptoms between parents of only children and parents of multiple children, this comparison approached significance $(p=0.55)$, such that minimization scores were higher among parents of only children than parents of children with at least one sibling. This suggests that parents of only children may be more likely to discount, criticize, or ignore their child's pain complaints and behaviors and send their children to school even when they are experiencing pain or illness. In fact, our study found that children with siblings were more likely to miss school. While it could be argued that children in multiple families may be more likely to become ill due to greater illness exposure, it is intriguing to speculate that the phenomenon we have uncovered (more parental minimization in response to only children's expressions of symptoms) may also contribute to this attendance behavior. It should also be noted that although parents were clearly electing to keep children with siblings home from school more frequently for abdominal symptoms, they were not giving their children more medications or taking them to the doctor more frequently. Speculation as to reasons for this phenomenon could go in many directions. For example, it could be suggested that parents of multiple children might evaluate symptoms of any one child in comparison to symptoms of their other children.

Finally, the fact that maternal psychological distress differed as a function of only child status is also intriguing. In our study, mothers of only children reported higher somatization, anxiety, and depression than mothers of multiple children, and the number of children was shown to be a significant predictor even after controlling for various demographic factors. It is not clear that this emotional distress is due to the child's status. It could be argued that mother's distress may have prevented them from having more children. Our analyses showed that the only child status alone, however, did not fully explain the somatization, anxiety, and depression scores. Mothers with IBS reported higher scores on all SCL-90 subscales compared to mothers without IBS. Maternal IBS status (i.e., having an IBS diagnosis) was also a significant predictor of somatization, anxiety, and depression. This makes intuitive sense, as mothers who themselves have an IBS diagnosis may suffer pain and other symptoms. One might expect that mothers with less than a college education, with multiple children, and single parenthood would experience the greatest emotional distress, but this was not our finding. While our t-test analyses initially indicated that mothers with less than a college education reported higher somatization and depression scores than college-educated mothers, maternal education was not a significant predictor in the regression analyses, which controlled for the effect of other variables. In a recent, non-peer reviewed study, maternal stress was higher in moms who had two or three children than in mothers of single children [49]. High parental stress can have negative outcomes for children, including health-related outcomes. For example, in a national US study, parent stress increased the likelihood for the child to present at pediatric emergency care [50]. During the 2020 pandemic, adults with children reported higher levels of stress than adults without children [51]. Parents also reported high levels of physical symptoms related to stress such as stomachaches, headaches, eating and sleeping problems [52]. When parents are sick, they model to their children how to respond to symptoms, which influences child illness behaviors and health outcomes [53-55]. This may suggest that any effect of only child status on child health outcomes may be mediated by parental distress, parental symptoms, and parental illness behaviors. There could also be other psychological factors which may be associated with a choice to have only one child. This needs to be examined in future studies. 
One limitation of this study lies in the self-report nature of the measures. Future research should endeavor to observationally measure parental responses to child symptom complaints and link these behaviors to the only child status. Additionally, this study focused on self-identified primary caregivers, and in this study those who identified as such were mothers. It would be interesting to examine the behaviors of fathers when their children complain of illness in only child situations. Furthermore, parent behaviors may change with time. For example, after birth, parent behaviors to their first born change in half of the parents, mostly negative [56]. These negative behaviors are a function of feeling exhausted and will likely change as the newborn matures.

Despite these considerations, this study represents an important methodological and conceptual shift in the literature examining the relationship between only child status and parental response to only children. Methodologically, this study examines specific child behaviors and specific parental behavioral responses of only children and their parents. Thus, it goes beyond more global examinations of traits of only children. Conceptually, this study also looks at these behaviors and responses in an area new to the only child literature-the development of illness symptoms and, ultimately, illness behavior and the parental factors that may, or may not, contribute toward this development. For instance, when a child reports a physiological experience to a parent, the parent may or may not respond. And if the parent responds, how they respond may set in place a process which can have a lasting effect on that child's symptom experience, quality of life, and disability. For example, a parent may, with their reaction, communicate "This is nothing to pay attention to", or "This is serious, and you should notice it whenever it occurs", and/or "You definitely should complain about this", and/or "You should curtail normal activities as a result of this", etc. All of these responses, with the exception of the first response, are likely to increase the likelihood that the child will notice the sensation in the future and react to it in a way that limits their regular daily events. Because the encouragement of illness behavior in childhood can also lead to high levels of inappropriate illness behavior in adulthood [18], the findings here may have implications not only for children, but also for these individuals in later life. Further research on specific parental behaviors which could contribute to other behaviors and traits of only children is one logical and productive future direction for this work.

Author Contributions: Conceptualization, R.L.L., T.B.M., S.L.L., M.A.L.v.T.; Methodology, R.L.L., T.B.M., K.K., S.L.L.; Validation, R.L.L., S.L.L., M.A.L.v.T.; Formal Analysis, T.B.M.; Investigation, R.L.L., S.L.L., T.B.M.; Resources, R.L.L.; Data Curation, T.B.M.; Writing-original draft preparation, R.L.L., T.B.M., S.L.L., M.A.L.v.T.; Writing—review and editing, R.L.L., T.B.M., K.K., S.L.L., M.A.L.v.T.; Visualization, T.B.M.; Supervision, R.L.L.; Project Administration, R.L.L.; Funding acquisition, R.L.L. All authors have read and agreed to the published version of the manuscript.

Funding: This research was funded by the National Institutes of Health, grant number R01 HD36069.

Institutional Review Board Statement: The Institutional Review Board at Group Health approved this study (IRB \#: HS-96-131). The study was conducted according to the guidelines of the Declaration of Helsinki, and approved by the Institutional Review Board of Group Health (IRB \# HS-96-13; approved through March 2008).

Informed Consent Statement: Informed consent was obtained from all subjects involved in the study.

Data Availability Statement: The data presented in this study are available on request from the corresponding author.

Conflicts of Interest: The authors declare no conflict of interest. 
Appendix A. SCL-90 Regression Scatterplots

Scatterplot

Dependent Variable: SCL90 Somatization scale raw score

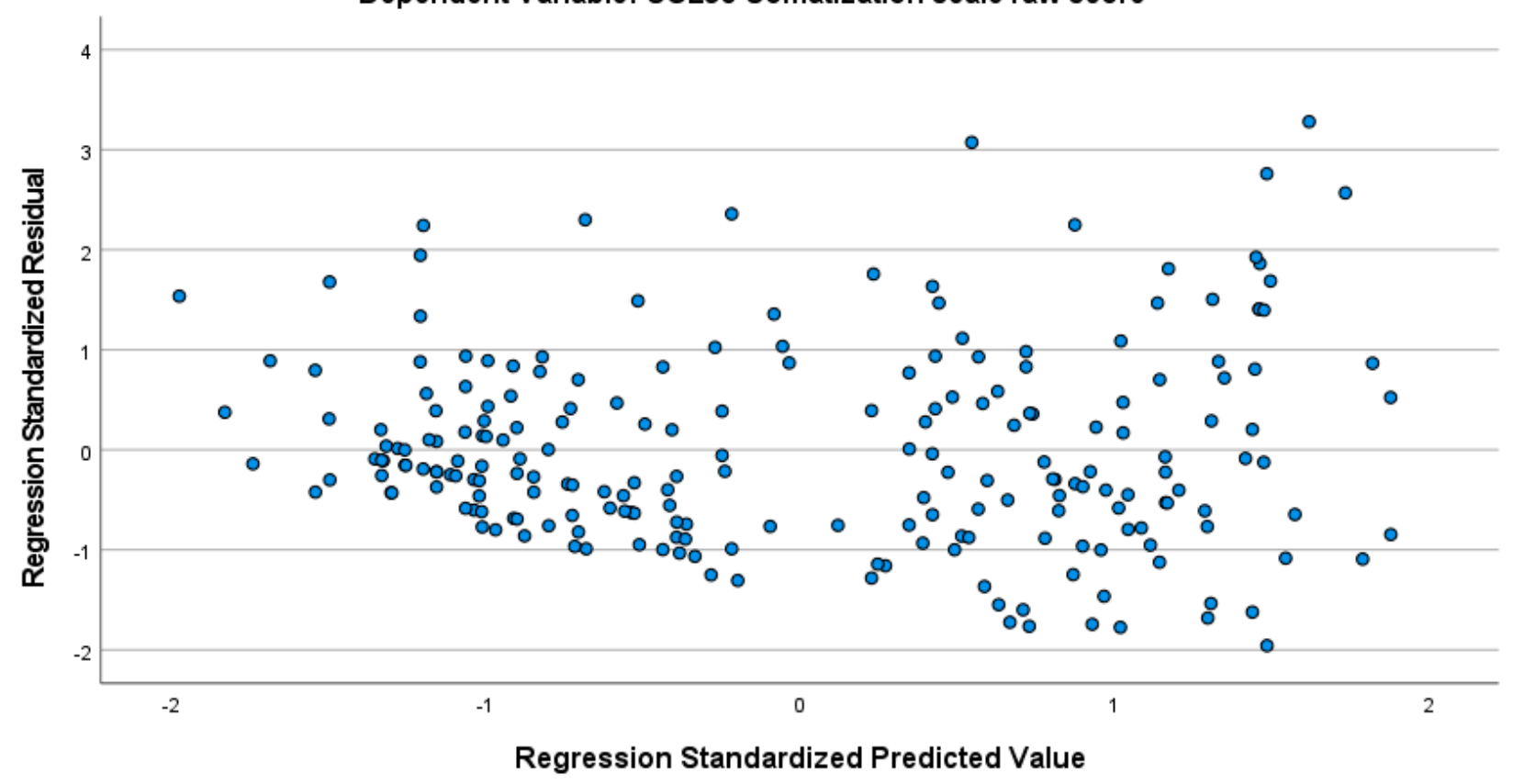

Figure A1. Scatterplot showing standardized residuals for SCL-90 Somatization scale.

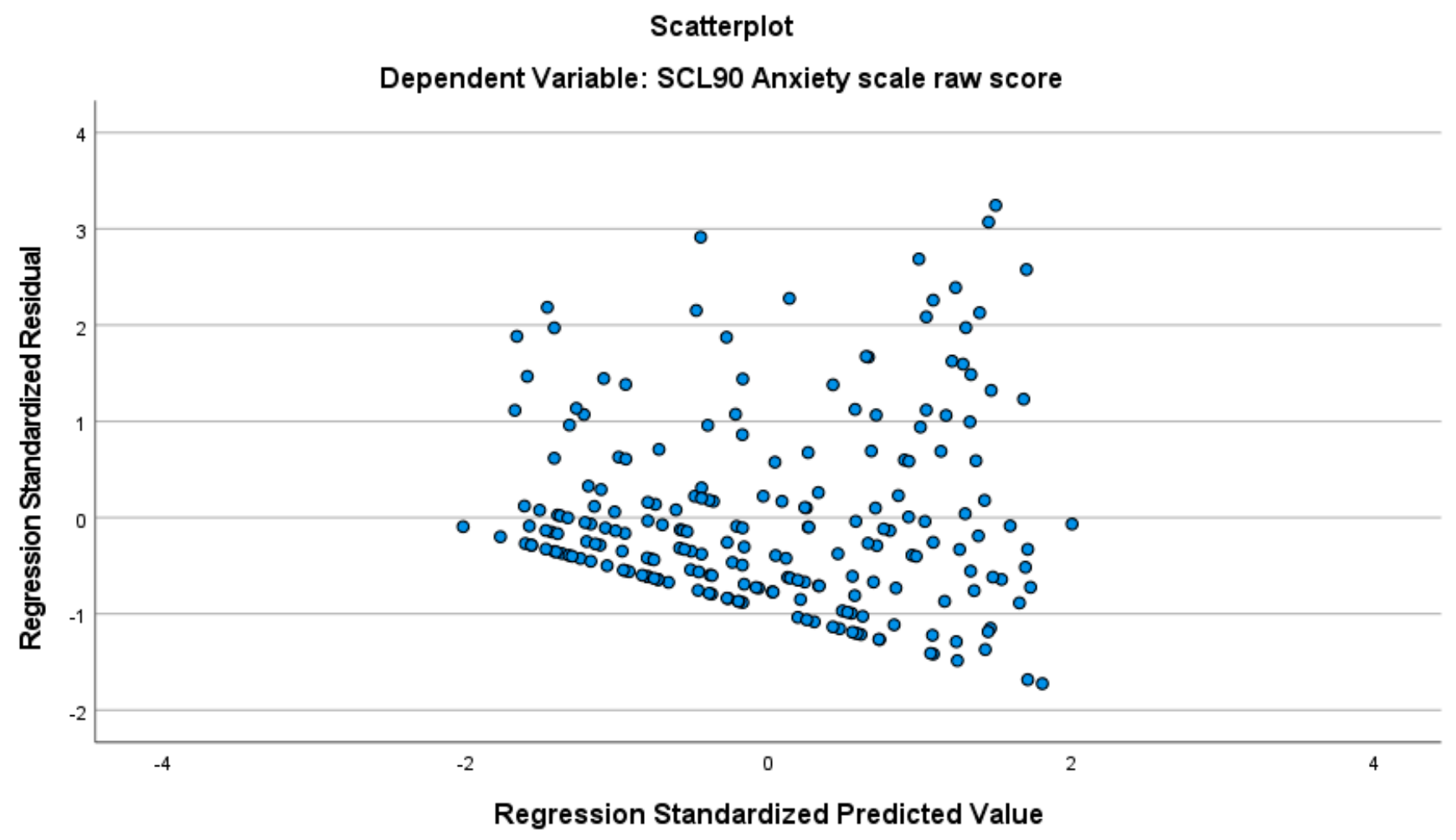

Figure A2. Scatterplot showing standardized residuals for SCL-90 Anxiety scale. 


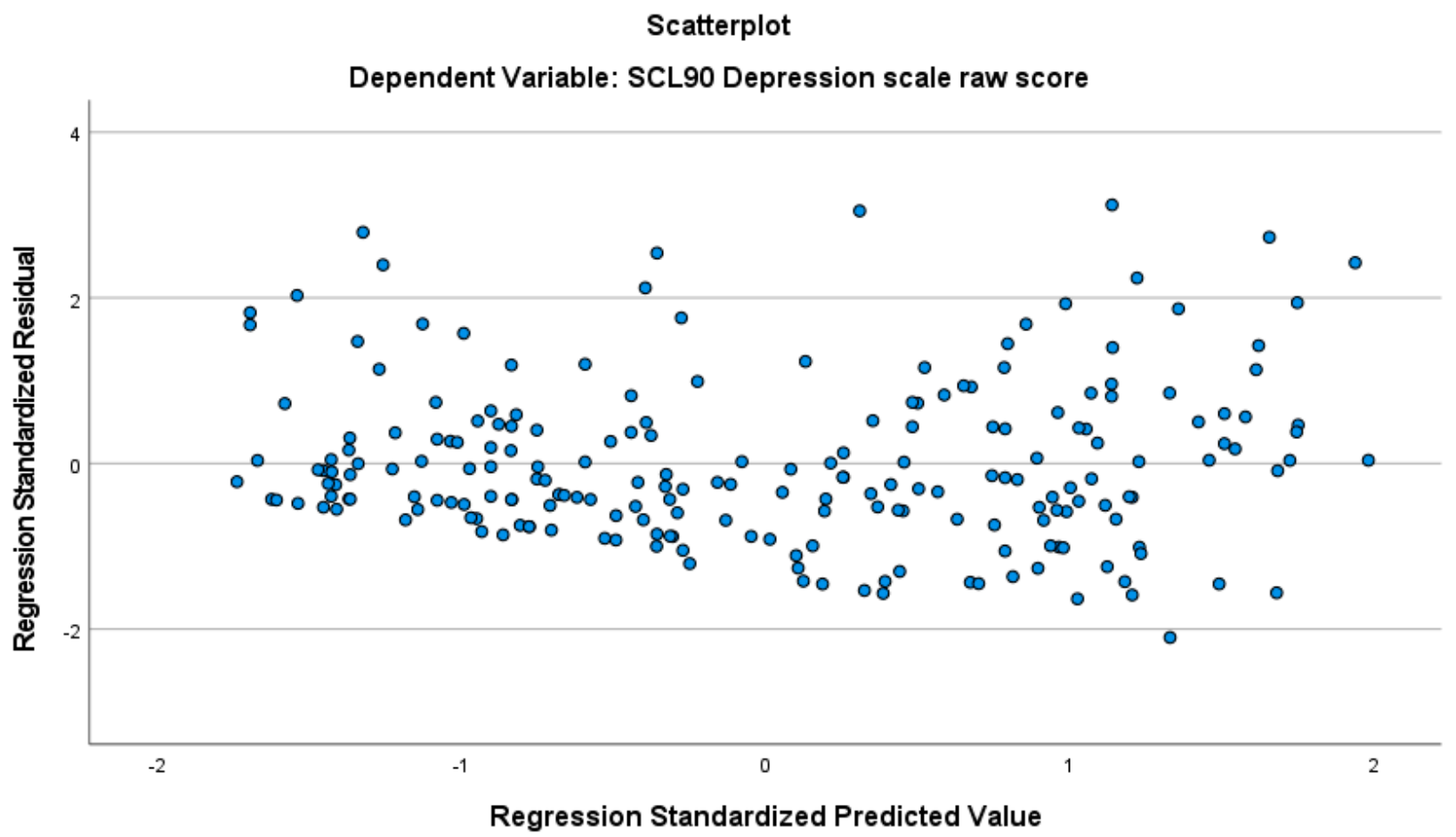

Figure A3. Scatterplot showing standardized residuals for SCL-90 Depression scale.

\section{References}

1. Kristensen, P.; Bjerkedal, T. Explaining the relation between birth order and intelligence. Science 2007, 316, 1717. [CrossRef] [PubMed]

2. Sulloway, F. Birth Order. In Evolutionary Family Psychology; Salmon, C., Shackelford, T., Eds.; Oxford University Press: Oxford, OH, USA, 2007; pp. 162-182.

3. Damian, R.I.; Roberts, B.W. The associations of birth order with personality and intelligence in a representative sample of U.S. high school students. J. Res. Personal. 2015, 58, 96-105. [CrossRef]

4. Jee-Yeon, J.; Lehmann, A.N.; Vidal-Fernandez, M. The early origins of birth order differences in children's outcomes and parental behavior. J. Hum. Resour. 2018, 53, 123-156.

5. Bohannon, E.W. The Only Child in a Family. Pedagog. Semin. 2012, 5, 475-496. [CrossRef]

6. Hartmann, C. Is Only-Child Syndrome Real? Sci. Am. 2019.

7. Tavares, M.B.; Fuchs, F.C.; Diligenti, F.; de Abreu, J.R.; Rohde, L.A.; Fuchs, S.C. Behavioral characteristics of the only child vs first-born and children with siblings. Rev. Bras. Psiquiatr. 2004, 26, 17-23. [CrossRef] [PubMed]

8. Richards, H.; Goodman, R. Are only children different? A study of child psychiatric referrals. A research note. J. Child Psychol. Psychiatry Allied Discip. 1996, 37, 753-757. [CrossRef] [PubMed]

9. Dufner, M.; Back, M.D.; Oehme, F.F.; Schmukle, S.C. The End of a Stereotype: Only Children Are Not More Narcissistic Than People With Siblings. Soc. Psychol. Personal. Sci. 2020, 11, 416-424. [CrossRef]

10. Foster, J.D.; Raley, J.R.; Isen, J.D. Further evidence that only children are not more narcissistic than individuals with siblings. Personal. Individ. Differ. 2020, 161. [CrossRef]

11. Stronge, S.; Shaver, J.H.; Bulbulia, J.; Sibley, C.G. Only children in the 21st century: Personality differences between adults with and without siblings are very, very small. J. Res. Personal. 2019, 83. [CrossRef]

12. Botzet, L.J.; Rohrer, J.M.; Arslan, R.C. Analysing effects of birth order on intelligence, educational attainment, big five and risk aversion in an Indonesian sample. Eur. J. Personal. 2020, 35, 234-248. [CrossRef]

13. Rohrer, J.M.; Egloff, B.; Schmukle, S.C. Examining the effects of birth order on personality. Proc. Natl. Acad. Sci. USA 2015, 112, 14224-14229. [CrossRef] [PubMed]

14. Townsend, F. Birth order and rebelliousness: Reconstructing the research in Born to Rebel. Politics Life Sci. 2000, 19, 135-156. [CrossRef]

15. Mechanic, D. Sex, illness, illness behavior, and the use of health services. Soc. Sci. Med. 1978, 12, 207-214. [CrossRef]

16. Drossman, D.A.; Li, Z.; Andruzzi, E.; Temple, R.D.; Talley, N.J.; Thompson, W.G.; Whitehead, W.E.; Janssens, J.; Funch-Jensen, P.; Corazziari, E.; et al. U.S. householder survey of functional gastrointestinal disorders. Prevalence, sociodemography, and health impact. Dig. Dis. Sci. 1993, 38, 1569-1580. [CrossRef] 
17. Sperber, A.D.; Bangdiwala, S.I.; Drossman, D.A.; Ghoshal, U.C.; Simren, M.; Tack, J.; Whitehead, W.E.; Dumitrascu, D.L.; Fang, X.; Fukudo, S.; et al. Worldwide Prevalence and Burden of Functional Gastrointestinal Disorders, Results of Rome Foundation Global Study. Gastroenterology 2021, 160, 99-114.e113. [CrossRef]

18. Lewis, C.E.; Lewis, M.A.; Lorimer, A.; Palmer, B.B. Child-initiated care: The use of school nursing services by children in an "adult-free" system. Pediatrics 1977, 60, 499-507.

19. Schor, E.; Starfield, B.; Stidley, C.; Hankin, J. Family health. Utilization and effects of family membership. Med. Care 1987, 25, 616-626. [CrossRef]

20. Levy, R.L.; Whitehead, W.E.; Von Korff, M.R.; Feld, A.D. Intergenerational transmission of gastrointestinal illness behavior. Am. J. Gastroenterol. 2000, 95, 451-456. [CrossRef] [PubMed]

21. van Tilburg, M.A.; Levy, R.L.; Walker, L.S.; Von Korff, M.; Feld, L.D.; Garner, M.; Feld, A.D.; Whitehead, W.E. Psychosocial mechanisms for the transmission of somatic symptoms from parents to children. World J. Gastroenterol. 2015, 21, 5532-5541. [CrossRef] [PubMed]

22. Shah, E.D.; Ballou, S.K. Health economic studies are important for patients with Irritable Bowel Syndrome and their gasteroenterologists. Clin. Gastroenterol. Hepatol. 2020, 19, 43-45. [CrossRef] [PubMed]

23. Black, C.J.; Ford, A.C. Global burden of irritable bowel syndrome: Trends, predictions and risk factors. Nat. Rev. Gastroenterol. Hepatol. 2020, 17, 473-486. [CrossRef] [PubMed]

24. Everhart, J.E.; Ruhl, C.E. Burden of digestive diseases in the United States part I: Overall and upper gastrointestinal diseases. Gastroenterology 2009, 136, 376-386. [CrossRef]

25. Everhart, J.E.; Ruhl, C.E. Burden of digestive diseases in the United States part II: Lower gastrointestinal diseases. Gastroenterology 2009, 136, 741-754. [CrossRef] [PubMed]

26. Elliott, L.; Thompson, K.A.; Fobian, A.D. A Systematic Review of Somatic Symptoms in Children With a Chronically Ill Family Member. Psychosom Med. 2020, 82, 366-376. [CrossRef]

27. Whitehead, W.E.; Winget, C.; Fedoravicius, A.S.; Wooley, S.; Blackwell, B. Learned illness behavior in patients with irritable bowel syndrome and peptic ulcer. Dig. Dis. Sci. 1982, 27, 202-208. [CrossRef]

28. Levy, R.L.; Whitehead, W.E.; Walker, L.S.; Von Korff, M.; Feld, A.D.; Garner, M.; Christie, D. Increased somatic complaints and health-care utilization in children: Effects of parent IBS status and parent response to gastrointestinal symptoms. Am. J. Gastroenterol. 2004, 99, 2442-2451. [CrossRef]

29. Claar, R.L.; Simons, L.E.; Logan, D.E. Parental response to children's pain: The moderating impact of children's emotional distress on symptoms and disability. Pain 2008, 138, 172-179. [CrossRef]

30. Logan, D.E.; Simons, L.E.; Carpino, E.A. Too sick for school? Parent influences on school functioning among children with chronic pain. Pain 2012, 153, 437-443. [CrossRef]

31. Sieberg, C.B.; Williams, S.; Simons, L.E. Do parent protective responses mediate the relation between parent distress and child functional disability among children with chronic pain? J. Pediatric Psychol. 2011, 36, 1043-1051. [CrossRef]

32. Bendersky, M.; Lewis, M. The impact of birth order on mother-infant interactions in preterm and sick infants. J. Dev. Behav. Pediatrics 1986, 7, 242-246. [CrossRef]

33. Ward, A.; Pratt, C. Psychosocial influences on the use of health care by children. Aust. N. Zeal. J. Public Health 1996, 20, 309-316. [CrossRef]

34. Kushnir, T. Parental anxiety and children's attendance at emergency departments in relation to the child's birth order. J. Soc. Psychol. 1984, 123, 123-129. [CrossRef]

35. Hawkin, S.; Kwong, J.C.; Deeks, S.L.; Crowcroft, N.S.; Ducharme, R.; Manuel, D.G.; Wilson, K. Association between birth order and emergency room visits and acute hospital admissions following pediatric vacination: A self-controlled study. PLoS ONE 2013, 8, e81070.

36. Sulloway, F. Born to Rebel: Birth Order Family Dynamics, and Creative Lives; Pantheon Books: New York, NY, USA, 1996.

37. Roberts, L.C.; Blanton, P.W. "I always knew mom and dad love me best": Experiences of only children. J. Individ. Psychol. 2001, $57,125-140$.

38. Lacy, B.E.; Patel, N.K. Rome criteria and a diagnostic approach to Irritable Bowel Syndrome. J. Clin. Med. 2017, 7, 99. [CrossRef]

39. Van Slyke, D.A.; Walker, L.S. Mothers' responses to children's pain. Clin. J. Pain 2006, 22, 387-391. [CrossRef]

40. Walker, L.S.; Zeman, J.L. Parental response to child illness behavior. J. Pediatric Psychol. 1992, 17, 49-71. [CrossRef] [PubMed]

41. Walker, L.S.; Levy, R.L.; Whitehead, W.E. Validation of a measure of protective parent responses to children's pain. Clin. J. Pain 2006, 22, 712-716. [CrossRef] [PubMed]

42. Derogatis, L.R. Symptom Checklist-90-R: Administrative Scoring and Procedures Manual; NCS Pearson: Minneapolis, MN, USA, 1994.

43. Gere, M.K.; Villabo, M.A.; Torgersen, S.; Kendall, P.C. Overprotective parenting and child anxiety: The role of co-occurring child behavior problems. J. Anxiety Disord. 2012, 26, 642-649. [CrossRef]

44. Lynch-Jordan, A.M.; Peugh, J.; Cunningham, N.R.; Trygier, J.R.; Kashikar-Zuck, S. Maternal protective parenting accounts for the relationship between pain behaviors and functional disability in adolescents. Clin. J. Pain 2018, 34, 1089-1095. [CrossRef]

45. Yamaguchi, N.; Kobayashi, J.; Tachikawa, H.; Sato, S.; Hori, M.; Suzuki, T.; Shiraishi, H. Parental representation in eating disorder patients with suicide. J. Psychosom. Res. 2000, 49, 131-136. [CrossRef]

46. Visser, L.; de Winter, A.F.; Vollebergh, W.A.M.; Verhulst, F.C.; Reijneveld, S.A. The impact of parenting styles on adolescent alcohol use: The TRAILS study. Eur. Addict. Res. 2013, 19, 165-172. [CrossRef] 
47. van Gastel, W.; Legerstee, J.S.; Ferdinand, R.F. The role of perceived parenting in familial aggregation of anxiety disorders in children. J. Anxiety Disord. 2009, 23, 46-53. [CrossRef]

48. Ishizuka, P. Social class, gender, and contemporary parenting standards in the United States: Evidence from a National Survey Instrument. Soc. Forces 2019, 98, 31-58. [CrossRef]

49. Mom Survey Says: Three is the Most Stressful Number of Kids. 2021. Available online: https://www.today.com/parents/momsurvey-says-three-most-stressful-number-kids-t127551 (accessed on 29 June 2021).

50. Raphael, J.L.; Zhang, Y.; Liu, H.; Giardino, A.P. Parenting stress in U.S. families: Implications for paediatric healthcare utilization. Child Care Health Dev. 2010, 36, 216-224. [CrossRef]

51. Stress in America 2020: A National Mental Health Crisis. 2020. Available online: https://www.apa.org/news/press/releases/ stress/2020/report-october (accessed on 29 June 2021).

52. van Tilburg, M.A.; Edlynn, E.; Maddalone, M.; van Kempen, K.; Diaz-Gonzalez de Ferris, M.; Thomas, J. High levels of stress due to the SARS-CoV-2 Pandemic among parents of children with and without chronic conditions across the USA. Child 2020, 7, 193. [CrossRef]

53. Levy, R.L.; Langer, S.L.; van Tilburg, M.A.; Romano, J.M.; Murphy, T.B.; Walker, L.S.; Mancl, L.A.; Claar, R.L.; DuPen, M.; Whitehead, W.E.; et al. Brief telephone-delivered cognitive behavioral therapy targeted to parents of children with functional abdominal pain: A Randomized Controlled Trial. Pain 2016, 158, 618-628. [CrossRef]

54. Levy, R.L.; van Tilburg, M.A.; Langer, S.L.; Romano, J.M.; Walker, L.S.; Mancl, L.A.; Murphy, T.B.; Claar, R.L.; Feld, S.I.; Christie, D.L.; et al. Effects of a cognitive behavioral therapy intervention trial to improve disease outcomes in children with Inflammatory Bowel Disease. Inflamm. Bowel Dis. 2016, 22, 2134-2148. [CrossRef]

55. Levy, R.L. Exploring the intergenerational transmission of illness behavior: From observations to experimental intervention. Ann. Behav. Med. 2011, 41, 174-182. [CrossRef]

56. Kojima, Y.; Irisawa, M.; Wakita, M. The impact of a second infant on interactions of mothers and firstborn children. J. Reprod. Infant Psychol. 2007, 23, 103-114. [CrossRef] 